Journal of Electronics and Informatics (2019)

Vol.01/ No. 02

Pages: $80-88$

http://www.irojournals.com/iroei/

DOI: https://doi.org/10.36548/jei.2019.2.003

\title{
TYPING EYES: A HUMAN COMPUTER INTERFACE TECHNOLOGY
}

\author{
A. Sathesh, \\ Department of EEE, \\ Eritrea Institute of Technology, \\ Eritrea. \\ Email: sathesh4you@gmail.com
}

\begin{abstract}
The human's beings always make use of their sensory modalities to effectively communicate or carry out their jobs. The humans use the sensory organs such as the ears, eyes mouth, including the hands to deliver a good verbal conversation. The human computer interface technology could also be made classier by involving the human voice, hands and eyes to access an application or control a device etc.; they paper puts forth the development of the human computer interface based on the eyes movement for typing the information without using the hand for typing, this could be very much useful for the patients with disabilities in the arms or affected by paralytic attacks for their regular works associated with the computers and can also be used by the normal people in security intensive applications, the evaluation results obtained for the proposed method using the MATLAB shows that the mean typing speed to be 30 characters per minute.
\end{abstract}

Keywords: Eye Tracker, 8051, Pupil Detector, HCI, EEG

\section{INTRODUCTION}

The human computer interaction based on the recognizing the gesture of the human organs is in existence form early 1990s. Among the parts of the body utilized in HCI, eye based HCI was more popular as the simple gaze would enable to start, stop and regulate the processing of the computers, and was very useful for people affected by disabilities. The controlling a computer interface through the eye was understood earlier as the extraction of the information about the person was gazing at. Initially Robert Jacob identified the eye-gaze to be an input modality to open a computing device; nowadays the eye-gaze is used to unlock the phone and the other portable devices [1].

The eye-gaze or the eyes put into action for typing a text is called the gaze typing or eye typing, it is mainly used by the people who suffer from motor neuron disabilities, strokes or the spinal cord injuries, dystrophy in the muscles. The eye typing Is found to be the simple as well as the only means of communication for the persons suffering from above disabilities and the aged persons facing a motor activity that is reduced, arthritis or tremors, the figure.1 below provides the applications hierarchy associated with the eye tracking[2].

ISSN: 2582-3825 (online)

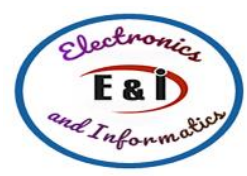


Journal of Electronics and Informatics (2019)

Vol.01/ No. 02

Pages: 80-88

http://www.irojournals.com/iroei/

DOI: https://doi.org/10.36548/jei.2019.2.003

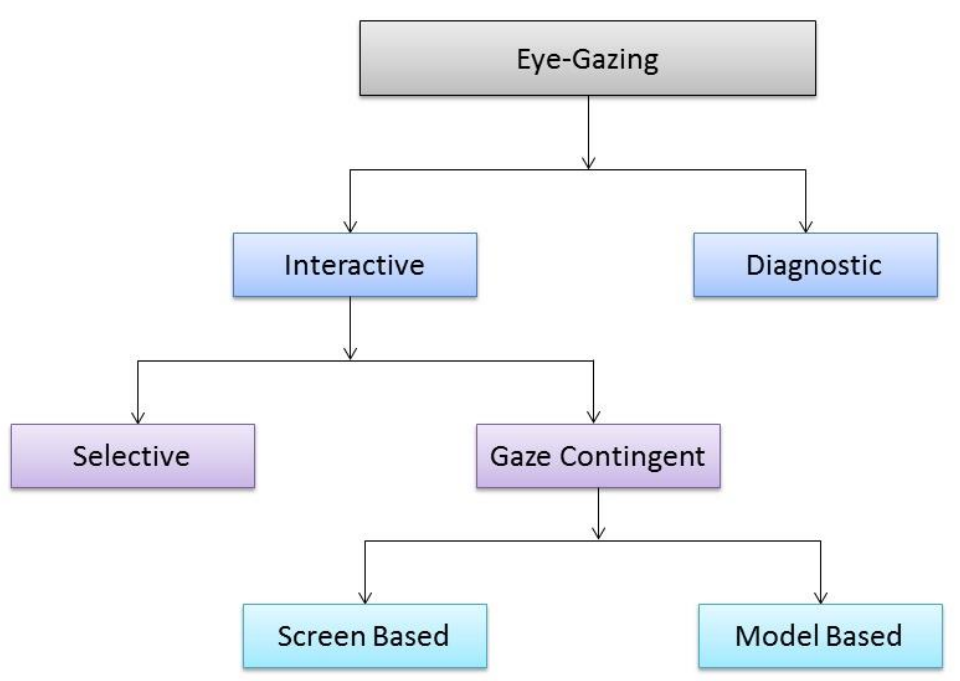

Figure.1 Eye Tracking Applications obtained from Duchowski, Andrew T and modified

People with the motor disabilities still has control in their eye movement, and these movement enables them to control and communicate through the computer [3], the best example of HCI would be Stephen Hawkins the theoretical physicist and cosmologist [4] the person who suffered from the amyotrophic lateral sclerosis (Paralysis whole body over years), he communicated with the people with the computer and the speech generating machine that converted his thoughts into the speech. Likewise the eye- gaze is used by many completely paralyzed people to effectively communicate with society using the computers and the eye gaze trackers.

The eye-gaze is the fastest pointing device, than the mouse or the other pointing devices that are in the computer, but the eye-gaze would not be much accurate as the mouse, as the accuracy in measurement is constrained by the dimensions of the fovea. There are particular challenges incurred by the eye-trackers such as the tracking accuracy, calibration drift, and the issues in distinguishing of intended input from the other eye movement that occur when using an interface [5].

Basically referring to the functioning of the human brain, the left hemisphere regulates the movements of the right side of the body and the right hemisphere regulates the left part of the body, but the eyes are exceptional as two eyes are present, as all the other sensory organs, the nerves in the eyes are also controlled by the brain. 
Journal of Electronics and Informatics (2019)

Vol.01/ No. 02

Pages: 80-88

http://www.irojournals.com/iroei/

DOI: https://doi.org/10.36548/jei.2019.2.003

So the paper put forth the utilization of the EEG (electroencephalogram) along with the EOG (electrooculography) to develop the typing eyes with the accuracy tracking of what is intended by the user and utilizing the 8051 processor to process the information and transmit the information using the Zigbee to the PC that is situated within 70 meters of distance.

The paper is arranged with the related works in section 2, the proposed design of typing eyes in section 3 the results in section 4 and conclusion in section 5 followed by references.

\section{RELATED WORKS}

Bulling, et al [1] "develops a mobile eye based HCI by designing a wearable EOG goggles to track the movement in the eyes", Singh, Jai et al [2] " present the multimodal human-computer interface (HCI) by combining an eye tracker with a soft-switch which may be considered as typically representing another modality. This multi-modal HCI is applied for text entry using a virtual keyboard appropriately designed in-house, facilitating enhanced performance"

Duchowski, et al [3] "reports the eye-tracking methodologies spanning three disciplines: neuroscience, psychology, and computer science, with brief remarks about industrial engineering and marketing. A breadth-first survey is given, proceeding from the diagnostic use of eye trackers to interactive application" Majaranta, Päivi, et al [5] presents the design issues in the typing system that was utilized so far.

Soltani, Sima et al [6] presents the designing of the novel wearable that is based on the EOG to recognize the human eye movements, Gautama, et al [7] presents the wheel chair control based on the tracking the eye movement. Sanjaya, et al [8] details the "Design and Experiment of Electrooculogram (EOG) System and Its Application to Control Mobile Robot."

the author Su et al [9] " has developed the "A low-cost vision-based human-computer interface for people with severe disabilities." the authors Valanarasu, eta 1 [10] and Duraipandian et al [11] have put for the use of the microcontrollers in transmitting the information's form one point to another.

ISSN: 2582-3825 (online) 
Journal of Electronics and Informatics (2019)

Vol.01/ No. 02

Pages: 80-88

http://www.irojournals.com/iroei/

DOI: https://doi.org/10.36548/jei.2019.2.003

Sivaganesan, et al [12] the details the "design and development AI-enabled edge computing for intelligent-IOT applications." Jacob, I. Jeena. et al [13] puts forth the "capsule network based biometric recognition system." and the author explains the "sleep pattern analysis and improvement using artificial intelligence and music therapy." in Pandian, M. Durai. et al [14]

S. Smys et al [15] provides the use of the "big data analytics for smart cloud-fog based applications." in the hospitals and the author Manoharan et al [16] address the necessity in the improving the precision and the delay reduction in the surgical robots. The above references from [10-16] are to be utilized in the future scope of the paper and the references [17-21] provides the basic steps in developing the proposed typing eyes for the dis abled and the elderly.

\section{SYSTEM MODEL}

The human's voluntary actions are always controlled and directed by the brain signals to so whenever a crippled or a disabled person wishes to type in a computer or control a system using the eyes the brain direct the actions that has to be done. So the system proposed utilizes the EOG and the EGG sensors to track the movement of the eyes and as well as identify the words gazed for typing respectively, the EOG enables the system to know where the eye -gaze is located and EEG enables to verify accuracy in the word selection. The 8051 used is programed to convert the signals obtained from the EOG and EEG to digital signal using the A/D convertor and then transmits, in the receiving side the decoder decodes the received signal and feeds it as input to the 8051 in the receiving end that is programmed to convert the signals in to appropriate words. The block diagram below in figure. 2 shows the architecture of the proposed typing eyes.

ISSN: 2582-3825 (online) 
Journal of Electronics and Informatics (2019)

Vol.01/ No. 02

Pages: $80-88$

http://www.irojournals.com/iroei/

DOI: https://doi.org/10.36548/jei.2019.2.003

\section{Transmitter side}

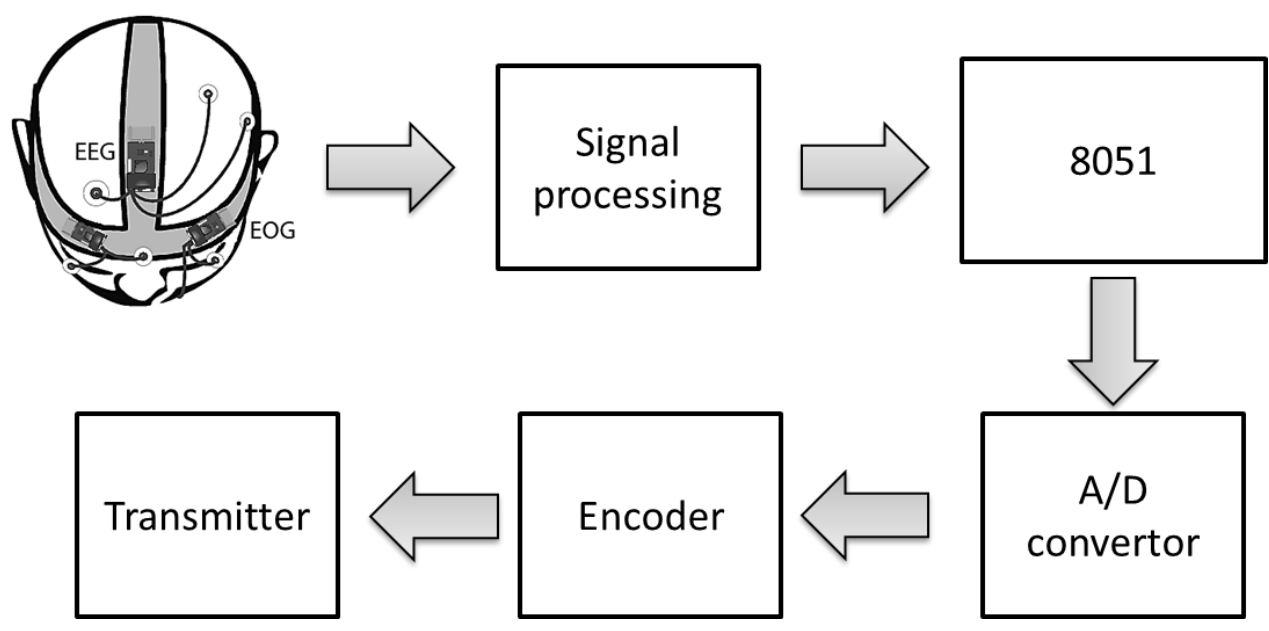

Fig.2 (a) Transmitter Side

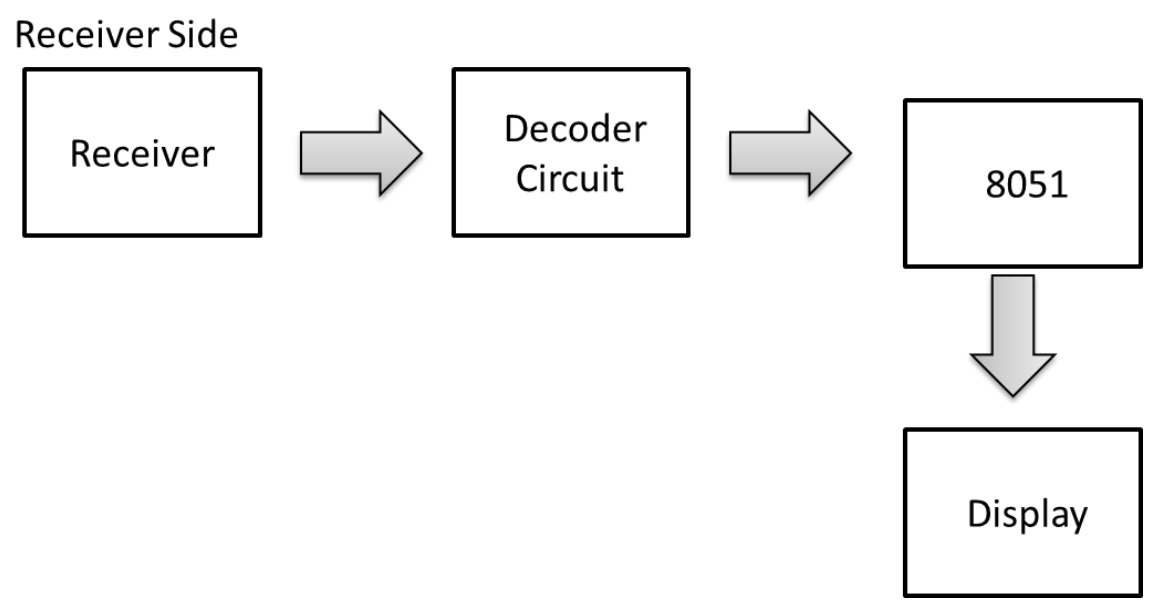

Fig .2 (b) Receiver sides

ISSN: 2582-3825 (online) 
Journal of Electronics and Informatics (2019)

Vol.01/ No. 02

Pages: 80-88

http://www.irojournals.com/iroei/

DOI: https://doi.org/10.36548/jei.2019.2.003

The overall architecture of the proposed system is shown in the Fig. 2(a) and 2(b), letters gazed by the persons paralyzed or the crippled person is monitored using the EOC and the EEG, The signal from the EEG and EOG is fed separately to the signal processing unit that is comprised of a preamplifier, filter and a post amplifier the preamplifier amplifies both the signals, the low pass filter, filters the noise (DC bias) in the circuit. The post amplifier amplifies the filtered signal to go along with the impedance of the 8051 processor [7] and feeds the signal to aurdino board that is further converted into digital form, encoded and transmitted for display using the Zigbee.

In the receiving side the decoder decodes the information and fed to the microcontroller that is programmed to recognize the digital signal and convert it to letters, the EOG signal enables to identify where the cursor is to be positioned and the EEG signals provides the details of the letter to be typed on the screen, the proposed system unlike the prevailing system does not use the virtual keyboards that causes the user to see a word to type instead, the proposed work allows the user to type what he thinks. So the use of key board can be avoided.

Though the system might be less time consuming and very useful as the person can type whatever is thought the controlling option is still under development as the person cannot erase a letter that is incorrectly thought or change the option that is wrong. So in future the paper would try developing the controlling actions implementing the artificial intelligence in the present system.

\section{RESULTS}

The results are obtained comparing the typing speed and the mean error rate when done using the hands, using the EOG and the virtual keyboard and using the EEG and EOG. The average typing speed and the mean error rate of every method is analyzed to find out the accuracy in typing. The tabulation below in table.1 shows the result achieved using the existing and proposed methods based on the dwell time, the dwell time in the existing cases are the time taken to select the keys and in the proposed it is the time taken to spell out the letters.

ISSN: 2582-3825 (online) 
Journal of Electronics and Informatics (2019)

Vol.01/ No. 02

Pages: $80-88$

http://www.irojournals.com/iroei/

DOI: https://doi.org/10.36548/jei.2019.2.003

\begin{tabular}{|c|c|c|c|c|c|c|}
\hline Methods & $\begin{array}{l}\text { Dwell } \\
\text { time } \\
\text { (ms) }\end{array}$ & 1000 & 1500 & 500 & 3000 & 2500 \\
\hline $\begin{array}{l}\text { Hand } \\
\text { typing }\end{array}$ & \multirow{3}{*}{$\begin{array}{l}\text { Typing } \\
\text { speed } \\
\text { (charact } \\
\text { ers/ } \\
\text { second } \\
\text { ) }\end{array}$} & $5 / 1$ & $6 / 2.5$ & $7 / 3$ & $8 / 3.5$ & $9 / 4$ \\
\hline $\begin{array}{l}\text { EOG } \\
\text { +Virtual } \\
\text { keyboard }\end{array}$ & & $7 / 1$ & $8 / 2.5$ & $9 / 3$ & $10 / 3.5$ & $12 / 4$ \\
\hline $\begin{array}{l}\text { EEG } \\
+E O G\end{array}$ & & $10 / 1$ & $12 / 2.5$ & $14 / 3$ & $16 / 3.5$ & $20 / 4$ \\
\hline $\begin{array}{l}\text { Hand } \\
\text { typing }\end{array}$ & \multirow{3}{*}{$\begin{array}{l}\text { Accura } \\
\text { cy in } \\
\text { typing } \\
\% 0\end{array}$} & 75 & 80 & 85 & 87 & 82 \\
\hline $\begin{array}{l}\text { EOG } \\
\text { +Virtual } \\
\text { keyboard }\end{array}$ & & 85 & 87 & 89 & 90 & 92 \\
\hline $\begin{array}{l}\text { EEG } \\
+E O G\end{array}$ & & 87 & 88 & 90 & 91 & 90 \\
\hline $\begin{array}{l}\text { Hand } \\
\text { typing }\end{array}$ & \multirow[t]{3}{*}{$\begin{array}{l}\text { Error } \\
\text { rate } \%\end{array}$} & 6 & 4.5 & 8.9 & 7.6 & 5.8 \\
\hline $\begin{array}{l}\text { EOG } \\
\text { +Virtual } \\
\text { keyboard }\end{array}$ & & 7.5 & 7.9 & 7.5 & 8.2 & 6.4 \\
\hline $\begin{array}{l}E E G \\
+E O G\end{array}$ & & 6.5 & 5.7 & 5.5 & 4.2 & 5.9 \\
\hline $\begin{array}{l}\text { Hand } \\
\text { typing }\end{array}$ & \multirow{3}{*}{$\begin{array}{l}\text { Standar } \\
\text { d } \\
\text { deviatio } \\
\text { n (o) }\end{array}$} & .98 & 1.24 & 3.44 & 7.56 & 2.22 \\
\hline $\begin{array}{l}\text { EOG } \\
\text { +Virtual } \\
\text { keyboard }\end{array}$ & & 1.09 & 2.33 & 4.82 & 8.22 & 3.26 \\
\hline $\begin{array}{l}\text { EEG } \\
+E O G\end{array}$ & & .99 & 2.45 & 5.32 & 8.54 & 4.64 \\
\hline
\end{tabular}

Table.1 Results Achieved

The total error rate $\left(T_{E r}\right)$ is defined as shown in the equation (1) below

$$
T_{E r}=\frac{I_{c}+C_{c r}}{A_{c}+I_{c}+C_{c r}}
$$

Where, $I_{c}$ is the uncorrected error, $C_{c r}$ is the corrected letters and the $A_{c}$ is the accurate letters, that are typed, the result represented in the table shows that the proposed typing has very less time consumption in typing, with the enhanced accuracy in typing and holds a little higher error rate compared to the existing system as the number of corrected letters are less due to lack of options in deleting the incorrect words that are typed.

So the paper takes this a future scope to develop a controlling action by integrating the proposed system using the artificial intelligence.

ISSN: 2582-3825 (online) 
Journal of Electronics and Informatics (2019)

Vol.01/ No. 02

Pages: 80-88

http://www.irojournals.com/iroei/

DOI: https://doi.org/10.36548/jei.2019.2.003

\section{CONCLUSION}

The paper has developed typing eyes by using the EEG (electroencephalogram) along with the EOG (electrooculography) to enhance the accuracy in typing doe with the help of the eyes. The system utilizes the EEG to recognize the letter thought by the person and uses the EOG to identify the position of the cursor, the 8051 microcontroller and the signal processing unit are used to effectively process the signal to present the correct words in the screen, the error occurrence in this system is very low as the typing is done base done based on the letters thought. The results obtained shows that the proposed method has a high accuracy and speed in typing compared to the previous methods and shows slight increase in the error rate as the correction process is not implemented in the system. So in future the paper would try developing the controlling actions implementing the artificial intelligence in the present system.

\section{References}

[1] Bulling, Andreas, and Hans Gellersen. "Toward mobile eye-based human-computer interaction." IEEE Pervasive Computing 9, no. 4 (2010): 8-12.

[2] Singh, Jai Vardhan, and Girijesh Prasad. "Enhancing an eye-tracker based human-computer interface with multi-modal accessibility applied for text entry." International Journal of Computer Applications 130, no. 16 (2015): 16-22.

[3] Duchowski, Andrew T. "A breadth-first survey of eye-tracking applications." Behavior Research Methods, Instruments, \& Computers 34, no. 4 (2002): 455-470.

[4] https://www.qriyo.com/blog/famous-people-with-disabilities/

[5] Majaranta, Päivi, and Kari-Jouko Räihä. "Twenty years of eye typing: systems and design issues." In Proceedings of the 2002 symposium on Eye tracking research \& applications, pp. 15-22. 2002.

[6] Soltani, Sima, and Amin Mahnam. "Design of a novel wearable human computer interface based on electrooculograghy." In 2013 21st Iranian Conference on Electrical Engineering (ICEE), pp. 1-5. IEEE, 2013.

ISSN: 2582-3825 (online)

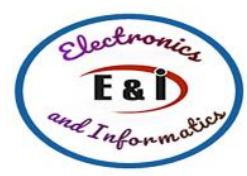


Journal of Electronics and Informatics (2019)

Vol.01/ No. 02

Pages: $80-88$

http://www.irojournals.com/iroei/

DOI: https://doi.org/10.36548/jei.2019.2.003

[7] Gautam, Gunda, Gunda Sumanth, K. C. Karthikeyan, Shyam Sundar, and D. Venkataraman. "Eye movement based electronic wheel chair for physically challenged persons." International journal of scientific \& technology research 3, no. 2 (2014): 206-212.

[8] Sanjaya, W. S. M., D. Anggraeni, R. Multajam, M. N. Subkhi, and I. Muttaqien. "Design and Experiment of Electrooculogram (EOG) System and Its Application to Control Mobile Robot." In IOP Conference Series: Materials Science and Engineering, vol. 180, no. 1, p. 012072. IOP Publishing, 2017.

[9] Su, Mu-Chun, Shi-Yong Su, and Gwo-Dong Chen. "A low-cost vision-based human-computer interface for people with severe disabilities." Biomedical Engineering: Applications, Basis and Communications 17, no. 06 (2005): 284-292.

[10] Valanarasu, Mr R. "SMART AND SECURE IOT AND AI INTEGRATION FRAMEWORK FOR HOSPITAL ENVIRONMENT." Journal of ISMAC 1, no. 03 (2019): 172-179.

[11] Duraipandian, M., and R. Vinothkanna Mr. "CLOUD BASED INTERNET OF THINGS FOR SMART CONNECTED OBJECTS." Journal of ISMAC 1, no. 02 (2019): 111-119.

[12] Sivaganesan, D. "DESIGN AND DEVELOPMENT AI-ENABLED EDGE COMPUTING FOR INTELLIGENT-IOT APPLICATIONS." Journal of trends in Computer Science and Smart technology (TCSST) 1, no. 02 (2019): 84-94.

[13] Jacob, I. Jeena. "CAPSULE NETWORK BASED BIOMETRIC RECOGNITION SYSTEM." Journal of Artificial Intelligence 1, no. 02 (2019): 83-94.

[14] Pandian, M. Durai. "SLEEP PATTERN ANALYSIS AND IMPROVEMENT USING ARTIFICIAL INTELLIGENCE AND MUSIC THERAPY." Journal of Artificial Intelligence 1, no. 02 (2019): 5462.

[15] Bestak, Robert, and S. Smys. "BIG DATA ANALYTICS FOR SMART CLOUD-FOG BASED APPLICATIONS." Journal of trends in Computer Science and Smart technology (TCSST) 1, no. 02 (2019): 74-83.

[16] Manoharan, Samuel, and Narain Ponraj. "PRECISION IMPROVEMENT AND DELAY REDUCTION IN SURGICAL TELEROBOTICS." Journal of Artificial Intelligence 1, no. 01 (2019): 28-36.

[17] https://www.ncbi.nlm.nih.gov/pmc/articles/PMC5808334/

[18] https://www.pnas.org/content/94/26/14965

[19] https://www.sciencedirect.com/science/article/pii/S2213158217302504

[20] https://onlinelibrary.wiley.com/doi/full/10.1002/9781118901731.iecrm0080

[21] https://www.tandfonline.com/doi/full/10.1080/23273798.2019.1580753

ISSN: 2582-3825 (online)

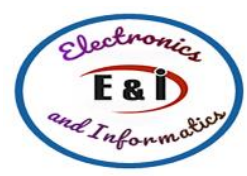

